\title{
The use of surface topography in the surveillance of adolescent idiopathic scoliosis: the influence of patient BMI on the reliability of curve measurement Patrick Knott*1, Steven Mardjetko ${ }^{2}$, Megan Dunn ${ }^{3}$, Jennifer Yatchek ${ }^{1}$ and Tatiana Anthony ${ }^{1}$
}

Address: ${ }^{1}$ Rosalind Franklin University of Medicine and Science, North Chicago, Illinois, USA, ${ }^{2}$ Rush University, Department of Orthopaedics, Chicago, Illinois, USA and ${ }^{3}$ Illinois Bone and Joint Institute, Morton Grove, Illinois, USA

* Corresponding author

from $5^{\text {th }}$ International Conference on Conservative Management of Spinal Deformities

Athens, Greece. 3-5 April 2008

Published: 15 January 2009

Scoliosis 2009, 4(Suppl I):OI5 doi:I0.II86/1748-7I6I-4-SI-OI5

This abstract is available from: http://www.scoliosisjournal.com/content/4/SI/OI5

(C) 2009 Knott et al; licensee BioMed Central Ltd.

\section{Background}

There are several methods available using surface topography to estimate the spinal curves in adolescent scoliosis patients. One new method, using the Ortelius 800 device, has been shown to be unreliable [1]. This study will analyze whether the reliability of measurements is related to the patient's Body Mass Index (BMI).

\section{Procedures}

Adolescent patients being screened or observed for scoliosis had their curves evaluated using standard radiographs. They also underwent an evaluation using the Ortelius 800 machine, which provides curve analysis and Cobb angles of the patient's spine. Finally, height and weight were obtained and BMI was calculated.

\section{Analysis}

For each patient, the difference between the Orthoscan measurement and the x-ray measurement was calculated, and then this difference was compared to the patient's BMI. Results showed that there was a negative correlation between BMI and the reliability of the measurements made using surface topography.

\section{Conclusion}

Procedures using surface topography to predict the magnitude of the Cobb angle in adolescents may be much less effective in patients with an elevated BMI.

\section{References}

I. Knott P, Mardjetko S, Nance D, Dunn M: Electromagnetic Topographical Technique of Curve Evaluation for Adolescent Idiopathic Scoliosis. Spine 2006, 31:24.

2. Doody MM, Lonstein JE: Breast Cancer Mortality After Diagnostic Radiography. Spine 2000, 25:2052-2063.

3. Nash CL, et al.: Risks of exposure to x-rays in patients undergoing long-term treatment for scoliosis. J Bone Joint Surg Am 1979, 61:37|-374.

4. Hoffman DA, et al.: Breast Cancer in Women with Scoliosis Exposed to multiple diagnostic X-Rays. J National Cancer Inst 1979, 8 I ( I 7): | 307-13 I2.

5. Dalia Dickman, Oren Caspi: Assessment of Scoliosis with Ortelius 800: Preliminary Results. Clinical Application Notes 200I:I-7. 